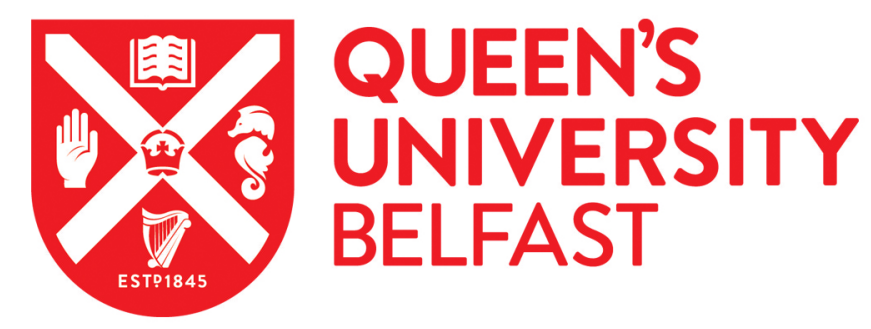

\title{
Association of dietary supplement use with specific micronutrient intakes among middleaged american men and women: the INTERMAP study
}

Archer, S. L., Stamler, J., Moag-Stahlberg, A., Van Horn, L., Garside, D., Chan, Q., Buffington, J. J., Dyer, A. R., \& Yarnell, J. (2005). Association of dietary supplement use with specific micronutrient intakes among middleaged american men and women: the INTERMAP study. Journal Amer Dietary Association, 105, 11061114.

Published in:

Journal Amer Dietary Association

Queen's University Belfast - Research Portal:

Link to publication record in Queen's University Belfast Research Portal

\section{General rights}

Copyright for the publications made accessible via the Queen's University Belfast Research Portal is retained by the author(s) and / or other copyright owners and it is a condition of accessing these publications that users recognise and abide by the legal requirements associated with these rights.

Take down policy

The Research Portal is Queen's institutional repository that provides access to Queen's research output. Every effort has been made to ensure that content in the Research Portal does not infringe any person's rights, or applicable UK laws. If you discover content in the Research Portal that you believe breaches copyright or violates any law, please contact openaccess@qub.ac.uk. 


\section{Current Research}

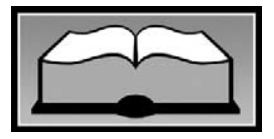

\section{Association of Dietary Supplement Use with Specific Micronutrient Intakes among Middle- Aged American Men and Women: The INTERMAP Study}

SUJATA L. ARCHER, PhD, RD; JEREMIAH STAMLER, MD; ALICIA MOAG-STAHLBERG, MSc, RD; LINDA VAN HORN, PhD, RD; DANIEL GARSIDE, MA; QUEENIE CHAN, MSc; JAMES J. BUFFINGTON, RD; ALAN R. DYER, PhD

\section{ABSTRACT}

Objective To assess dietary supplement use and its association with micronutrient intakes and adequacy among 2,195 US men and women aged 40 to 59 years from eight diverse population samples surveyed by the International Population Study on Macronutrients and Blood Pressure. Design Four 24-hour dietary recalls were collected, including information on dietary supplements. The Nutrition Data System (NDS) was used for nutrient analyses. Supplements not in NDS were classified separately (nonNDS). Intake of non-NDS supplements was documented. Participants were classified as not supplement users and supplement users, subclassified-due to concerns about nutritional value-as users of NDS supplements only (mostly vitamins and minerals) and users of non-NDS supplements (eg, botanicals, animal products, and enzymes). To assess effects of supplement use on micronu-

S. L. Archer is a research professor, J. Stamler is a professor emeritus, A. Moag-Stahlberg is an adjunct professor, L. Van Horn is a professor, D. Garside is an instructor and research programming manager, J. J. Buffington is a project coordinator, and A. R. Dyer is a professor with the Department of Preventive Medicine, Northwestern University Feinberg School of Medicine, Chicago, IL. Q. Chan is a senior statistical analyst with the Department of Epidemiology and Public Health, Imperial College, London, UK.

Address correspondence to: Sujata L. Archer, PhD, RD, Department of Preventive Medicine, Northwestern University Feinberg School of Medicine, 680 N Lake Shore Dr, No. 1102, Chicago, IL 60611. E-mail: s-archer@northwestern.edu

Copyright $(92005$ by the American Dietetic

\section{Association.}

0002-8223/05/10507-0005\$30.00/0

doi: 10.1016/j.jada.2005.04.010 trient intake and adequacy, mean intakes from supplements, foods, and foods plus supplements were compared with Dietary Reference Intakes.

Participants Two thousand one hundred ninety-five US participants; 1,136 used supplements.

Statistical analyses $\chi^{2}$ tests, multivariate logistic regression, and means were used to assess differences in and factors related to supplement use and to determine dietary adequacy.

Results Supplement use was more common among women, older participants, more educated participants, and Asian Americans. Body mass index and current cigarette smoking were significantly and inversely associated with supplement use; past smoking and education were significantly and positively associated with supplement use. Intake from foods plus supplements was considerably higher than from foods alone for vitamins $\mathrm{A}, \mathrm{C}$, and $\mathrm{E}$; niacin; folate; and iron.

Conclusions Supplement use is common among middleaged Americans and sizably increases daily intakes of several micronutrients. These data underscore the importance of dietary supplement assessment.

$J$ Am Diet Assoc. 2005;105:1106-1114.

pproximately $40 \%$ of Americans consume dietary supplements (1). Reports from the Third National Health and Nutrition Examination Survey indicate that supplement users are more likely to be children between the ages of 1 and 5 years and middle-aged and older adults (2). From 1994 to 2000, sales of supplements grew by $80 \%$ to an estimated $\$ 15.7$ billion (3). Most studies on dietary supplements have focused on populations from specific geographic areas or used instruments with predetermined lists of supplements, thereby limiting scope of supplement intake assessment (4-8). National nutrition monitoring surveys, like the Continuing Survey of Food Intakes by Individuals have been criticized for placing little emphasis on consumer use of dietary supplements (9). 
Reasons for supplement use include a wish to decrease susceptibility to disease, improve personal health, and avoid dietary deficiencies $(10,11)$. Although some studies found that people using supplements generally have high total intakes of vitamins and minerals compared to nonusers of supplements, this has not been reported consistently (12-14).

It is also unclear what the patterns of supplement intake are by age, sex, ethnicity, socioeconomic status, lifestyle traits, and biomedical traits (eg, smoking, body mass index [BMI], and blood pressure). Although national surveys have documented supplement use among some minority groups, others have not been represented.

With Dietary Reference Intakes (DRIs) now established for many nutrients, nutritional adequacy is being viewed in a fresh light (15). The DRIs define not only Adequate Intake (AI) levels but also Estimated Average Requirements (EARs), Recommended Dietary Allowances, and Upper Limits (ULs) for many nutrients, maximum daily intakes deemed safe (unlikely to increase risk of adverse effects) (16-20). Little information is available about the relations between dietary supplement use and nutrient intake and adequacy/excess in middle-aged US adults. Also, little information is available on intake of the wide range of supplements of varying nutritional merit being purchased and ingested by Americans.

This report uses data from the International Population Study on Macronutrients and Blood Pressure (INTERMAP) to focus on two issues: use of vitamin-mineral and other supplements by middle-aged US men and women aged 40 to 59 years of diverse ethnic, socioeconomic, geographic, lifestyle, and biomedical backgrounds from eight population samples nationwide, and the influence of supplement use on total intakes and adequacy/excess.

\section{METHODS}

INTERMAP is an international, cross-sectional epidemiologic study of 4,680 men and women aged 40 to 59 years from 17 diverse population samples surveyed in 1997 to 1999 in Japan, the People's Republic of China, the United Kingdom, and the United States (about 275 persons per sample) (21). The general aim is to clarify influences of multiple nutrients on blood pressure over and above established effects of sodium, potassium, alcohol, and BMI (21). Four in-depth, 24-hour dietary recalls were completed during a 3- to 6 -week period, with collection of detailed data on all foods, beverages, and dietary supplements consumed (22). All procedures were conducted in accordance with INTERMAP protocols approved by the institutional review boards at each center and informed signed consents were received from all participants. This report focuses on dietary supplement intake among US participants. In the United States there were 2,195 participants (1,102 men and 1,093 women) from eight samples diverse in location, ethnicity, and socioeconomic status.

All dietary supplement data were obtained during dietary data collection. During the 24-hour dietary recall, all reported foods/beverages and selected supplements (mostly vitamins and minerals) were directly computerized by the interviewer using the Nutrition Data System (NDS) (version 29, 1996, Nutrition Coordinating Center, University of Minnesota, Minneapolis). Intake by each participant of 104 nutrients from foods/beverages was computed (22). Of the four 24-hour dietary recalls, two were done on consecutive days and then another two on consecutive days approximately 3 weeks later (window of 2 to 6 weeks). One recall day was designed to be immediately after the weekend or a day off to assess any possible variation in diet during days off. All recalls were collected in a standardized way by centrally trained and certified local interviewers, supervised by centrally trained and certified site nutritionists, the country nutritionist, and the international nutrition coordinator. Details on quality control of dietary data collection are published elsewhere (22). Briefly, at each visit the interviewer asked the participant if he/she had taken any vitamins, minerals, tonics, or supplements. Supplements encompassed vitamin/mineral and other products purchased over the counter. If the reply was affirmative, a dietary supplement form was completed. The participant was also asked to bring to the next clinic visit all vitamin, mineral, and other supplements he/she was currently taking. For each dietary supplement, name, description, amount, and frequency of use were recorded for that day. After collecting the information, the interviewer reviewed with the participant each supplement reported, confirming name, unit, and dosage. In the United States, the interviewer then checked to see if the supplement was listed in NDS. If it was, this was noted on the form and the information was entered in the computer. If there was a supplement not in NDS, this was detailed on the form. A separate supplement ingredient form was completed for each supplement not in NDS, documenting its ingredients and dosage from the product label.

In NDS version 29 there were 60 nutrient codes for supplements encompassing specified quantities of mostly vitamins and minerals generally recognized as important nutritionally and meriting ingestion as supplements. For non-NDS dietary supplements, a separate computerized database was developed with all information from product labels entered on the supplement ingredient form. Non-NDS-listed supplements were often made up of materials of uncertain merit (herbals/botanicals, animal products, phospholipids, enzymes, as well as minerals and vitamins) were detailed in computer entries. Often for these supplements, no information was obtainable on ingredients and/or their amounts; this fact was also entered into the computer. Thus, comprehensive collection and computerization of both NDS and non-NDS supplements yielded detailed information on all supplements reported by participants during all four dietary recalls. For purposes of quality control, all data (100\%) from supplement ingredient forms were reentered and checked. All revisions were documented. An additional, randomly selected $20 \%$ were reentered for a second time as a double check.

For analyses, participants were first dichotomized by use or nonuse of any supplement. Users were divided into users of NDS-listed supplements only and users of nonNDS-listed supplements (without or with concomitant use of NDS-listed supplements). NDS-listed supplements were composed almost exclusively of vitamins and minerals of known amounts.

$\chi^{2}$ analyses were performed to assess differences in supplement use by sex, age, education, ethnicity, and sample. Logistic regression was also done adjusted for 


\begin{tabular}{|c|c|c|c|c|c|}
\hline Characteristic & $\begin{array}{l}\text { No } \\
\text { supplement }\end{array}$ & $\begin{array}{l}\text { Any dietary } \\
\text { supplement }\end{array}$ & $\begin{array}{l}\text { NDS }^{\mathrm{a}} \text {-listed } \\
\text { supplement only }\end{array}$ & $\begin{array}{l}\text { Non-NDS-listed } \\
\text { supplement }\end{array}$ & $P$ value ${ }^{\text {b }}$ \\
\hline & $\longleftarrow$ & 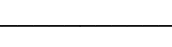 & $-\%$ & $\longrightarrow$ & \\
\hline \multicolumn{6}{|c|}{$10+2+2+5$} \\
\hline Male & 53 & 46 & 23 & 23 & \\
\hline Female & 43 & 56 & 34 & 22 & $<.001$ \\
\hline \multicolumn{6}{|l|}{ Age (y) } \\
\hline $40-49$ & 52 & 48 & 24 & 23 & \\
\hline $50-59$ & 44 & 56 & 34 & 22 & $<.001$ \\
\hline \multicolumn{6}{|l|}{ Education (y) } \\
\hline$<12$ & 69 & 31 & 21 & 10 & \\
\hline 12 & 54 & 46 & 28 & 19 & \\
\hline $13-15$ & 47 & 53 & 31 & 22 & \\
\hline 16 & 47 & 53 & 28 & 24 & \\
\hline$>16$ & 42 & 58 & 30 & 28 & $<.001$ \\
\hline \multicolumn{6}{|l|}{ Ethnicity } \\
\hline African American & 59 & 41 & 27 & 14 & \\
\hline Asian American & 37 & 63 & 31 & 32 & \\
\hline All Hispanic American & 57 & 43 & 22 & 21 & \\
\hline Hispanic white American & 52 & 48 & 25 & 23 & \\
\hline Hispanic African American & 61 & 39 & 19 & 20 & \\
\hline Non-Hispanic white American & 46 & 54 & 31 & 23 & \\
\hline Other American & 55 & 45 & 23 & 22 & $<.001$ \\
\hline \multicolumn{6}{|l|}{ Sample } \\
\hline Baltimore, MD & 56 & 44 & 31 & 13 & \\
\hline Chicago, IL & 43 & 57 & 30 & 27 & \\
\hline Corpus Christi, TX (Hispanic American) & 58 & 42 & 22 & 20 & \\
\hline Corpus Christi, TX (Non-Hispanic American) & 44 & 56 & 21 & 35 & \\
\hline Honolulu, HI & 33 & 67 & 31 & 36 & \\
\hline Jackson, MS & 55 & 45 & 26 & 19 & \\
\hline Minneapolis, MN & 47 & 53 & 39 & 14 & \\
\hline Pittsburgh, PA & 51 & 49 & 34 & 15 & $<.001$ \\
\hline
\end{tabular}

age, sex, education, and sample to assess lifestyle and biomedical factors related to any, NDS-only, and nonNDS supplement use. To assess dietary adequacy, mean daily intakes from foods, supplements, and foods plus supplements for multiple nutrients were calculated for users and nonusers of supplements and compared with DRIs. Of the new DRI categories, EARs were used here for all micronutrients except calcium, for which only AIs are available $(17,18)$

The number of supplement users who reached ULs for selected micronutrients was also calculated using SAS version 8.0 (1999, SAS Institute, Inc, Cary, NC) for all analyses.

\section{RESULTS}

Of all 2,195 US INTERMAP participants, 1,136 (52\%) reported use of dietary supplements; 640 (29\%) used NDS-listed supplements only, 496 (23\%) non-NDS-listed supplements. The latter encompassed 920 products with 1,009 specified ingredients; among these there were 294 brand-name products with unknown ingredients or amounts. Some of these products were proprietary formulas with listed ingredients but no amounts; proprietary blends stating only "proprietary protein blend" or "proprietary blend," without ingredients; supplements with no amounts for some ingredients; supplements with ingredients but no specific amounts per serving size; supplements with unit amounts that were uninterpretable (eg, $6 \times 8 \%$ ); and supplements that just stated serving size as "one dose" without amounts. Some of the most frequently ingested herbal/botanical/other supplements included gingko biloba, ginseng, bioflavonoids, and phospholipids.

\section{Relation of Demographic Characteristics to Supplement Use}

There were significant differences in supplement use by sex, age, education, ethnicity, and sample $(P<.001)$ for any dietary supplement use, NDS-listed dietary supplements only, and non-NDS-listed supplements (Table 1). More women than men used supplements (56\% vs $46 \%$ ). In the 50- to 59-year age group, 56\% used supplements; $48 \%$ in the 40 - to 49 -year age group used supplements. Of 


\begin{tabular}{|c|c|c|c|c|c|c|c|c|c|}
\hline \multirow[b]{2}{*}{ Variable } & \multicolumn{3}{|c|}{$\begin{array}{l}\text { Factors Related to any } \\
\text { Supplement Use }\end{array}$} & \multicolumn{3}{|c|}{$\begin{array}{l}\text { Factors Related to NDS-only } \\
\text { Supplement Use }\end{array}$} & \multicolumn{3}{|c|}{$\begin{array}{l}\text { Factors Related to non-NDS } \\
\text { Supplement Use }\end{array}$} \\
\hline & $\mathbf{O R}^{\mathbf{b}}$ & $95 \% \mathrm{Cl}^{\mathrm{c}}$ & $P$ value & $\mathbf{O R}$ & $95 \% \mathrm{Cl}$ & $P$ value & $\mathbf{O R}$ & $95 \% \mathrm{CI}$ & $P$ value \\
\hline Body mass index ${ }^{d}$ & 0.87 & $(0.80-0.95)$ & .0027 & 1.06 & $(0.96-1.17)$ & .2670 & 1.14 & $(1.02-1.28)$ & .0183 \\
\hline Special diet (yes/no) & 1.32 & (1.05-1.66) & .0163 & 0.96 & $(0.75-1.23)$ & .7493 & 0.72 & $(0.55-0.93)$ & .0133 \\
\hline Current smoker (yes/no) & 0.63 & $(0.49-0.80)$ & .0001 & 1.27 & $(0.96-1.67)$ & .0922 & 1.58 & $(1.15-2.16)$ & .0045 \\
\hline Exsmoker (yes/no) & 1.47 & $(1.21-1.78)$ & $<.0001$ & 0.78 & $(0.63-0.95)$ & .1510 & 0.79 & $(0.63-0.98)$ & .0347 \\
\hline Current drinker (yes/no) & 1.16 & $(0.96-1.41)$ & .1286 & 0.81 & $(0.66-1.01)$ & .0588 & 1.03 & $(0.82-1.30)$ & .8057 \\
\hline Exdrinker (yes/no) & 1.02 & $(0.82-1.27)$ & .8763 & 1.19 & $(0.93-1.53)$ & .1611 & 0.79 & $(0.61-1.03)$ & .0774 \\
\hline Disease diagnosis (yes/no) & 1.11 & $(0.93-1.33)$ & .2553 & 0.77 & $(0.63-0.93)$ & .0079 & 1.19 & $(0.96-1.48)$ & .1087 \\
\hline \multicolumn{10}{|l|}{ High blood pressure/CVD ${ }^{\mathrm{e}}$} \\
\hline treatment (yes/no) & 1.25 & $(1.01-1.54)$ & .0378 & 0.64 & $(0.15-0.80)$ & .0001 & 1.30 & $(1.00-1.68)$ & .0472 \\
\hline Diabetes (yes/no) & 1.32 & $(0.96-1.82)$ & .0915 & 1.01 & $(0.71-1.43)$ & .9724 & 0.61 & $(0.39-0.96)$ & .0305 \\
\hline High blood pressure (yes/no) & 0.89 & $(0.73-1.07)$ & .2028 & 1.38 & $(1.12-1.69)$ & .0021 & 0.81 & $(0.64-1.01)$ & .0629 \\
\hline Heart disease (yes/no) & 0.81 & $(0.56-1.16)$ & .2532 & 1.52 & $(1.04-2.20)$ & .0294 & 0.79 & $(0.50-1.24)$ & .3038 \\
\hline Stroke (yes/no) & 1.12 & $(0.56-2.25)$ & .7568 & 1.12 & $(0.53-2.36)$ & .7756 & 0.72 & $(0.29-1.79)$ & .4740 \\
\hline \multicolumn{10}{|c|}{ 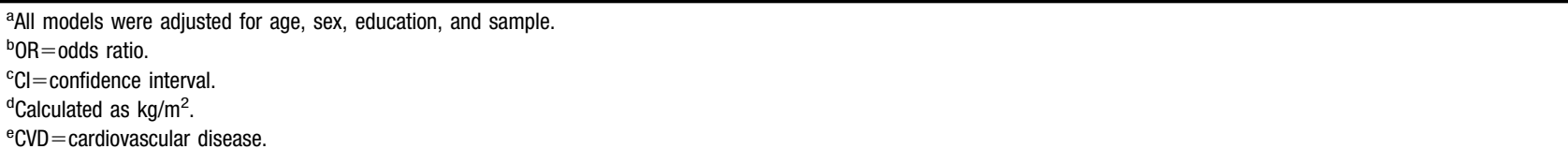 } \\
\hline
\end{tabular}

men, $23 \%$ reported consuming NDS-listed supplements only, $23 \%$ reported use of non-NDS-listed supplements; of women, 34\% reported using NDS-listed supplements only, $22 \%$ reported use of non-NDS supplements. Similar patterns of NDS only and non-NDS-supplement use were observed by age.

Asian Americans, primarily East Asians (282 of 318, mainly from the Japanese-American sample in Honolulu, HI) were the most frequent users of supplements (63\%); Hispanic African Americans were the least frequent (39\%) (Table 1). Use of NDS-listed supplements only ranged from 31\% (Asian Americans and non-Hispanic white Americans) to 19\% (Hispanic African Americans); use of non-NDS-listed supplements, from 32\% (Asian Americans) to $14 \%$ (African Americans).

Use of supplements varied considerably across the eight samples (Table 1). The Honolulu, HI, sample of Japanese Americans reported the highest supplement use (67\%); the Corpus Christi Hispanic-American sample reported the lowest (42\%). Minneapolis, MN, participants were the highest users of NDS-listed supplements only (39\%); Corpus-Christi non-Hispanic Americans were the lowest $(21 \%)$. Honolulu, HI, participants were the highest users of non-NDS-listed supplements (36\%); Baltimore, MD, the lowest (13\%).

\section{Relation of Lifestyle and Biomedical Traits, Disease Diagnoses, and Treatment Status to Supplement Use}

In multiple logistic analyses controlled for age, sex, education, and sample, former smoking (compared to never smoking) was associated positively and significantly with any, NDS-only, and non-NDS supplement use, whereas the relationship of current smoking (vs nonsmoking) status was significantly inverse (Table 2).
Overweight/obesity was associated with less frequent supplement use (Table 2). BMI was also inversely related to NDS-only and non-NDS supplement use (Table 2). Persons reporting consumption of a special diet were more likely to use supplements than others. Current drinkers (vs nondrinkers) tended to be more frequent supplement users, especially of NDS-listed supplements.

Persons with diagnosed diabetes or receiving antihypertensive drug treatment were more frequent consumers of supplements (Table 2). In contrast, among those with diagnosed heart disease or high blood pressure, there was an inverse association with NDS-only supplement use.

\section{Vitamin Intakes from Foods, Supplements, and Foods Plus Supplements}

The most commonly consumed vitamins from supplements were vitamins C, E, B-6, and B-12. For vitamins A and $\mathrm{C}$, and niacin, average intakes from foods only exceeded EARs, but not for vitamin E and folate (Table 3). Dietary intakes of vitamins from foods were on average higher among supplement users than nonusers for vitamin C and folate. Vitamins A, C, and E; niacin; and folate intakes were substantially higher from foods plus supplements than from foods alone (eg, total folate intake for female supplement users was $591 \mu \mathrm{g} /$ day, whereas from foods alone it was $269 \mu \mathrm{g} / \mathrm{day}$ ). Total intakes of vitamins among supplement users on average were considerably above $100 \%$ of EARs, whereas for nonusers they were below the EARs for vitamin $\mathrm{E}$ and folate. For supplement users of vitamins $\mathrm{A}, \mathrm{C}$, and $\mathrm{E}$ and niacin, total intakes were several-fold greater than the EARs. 


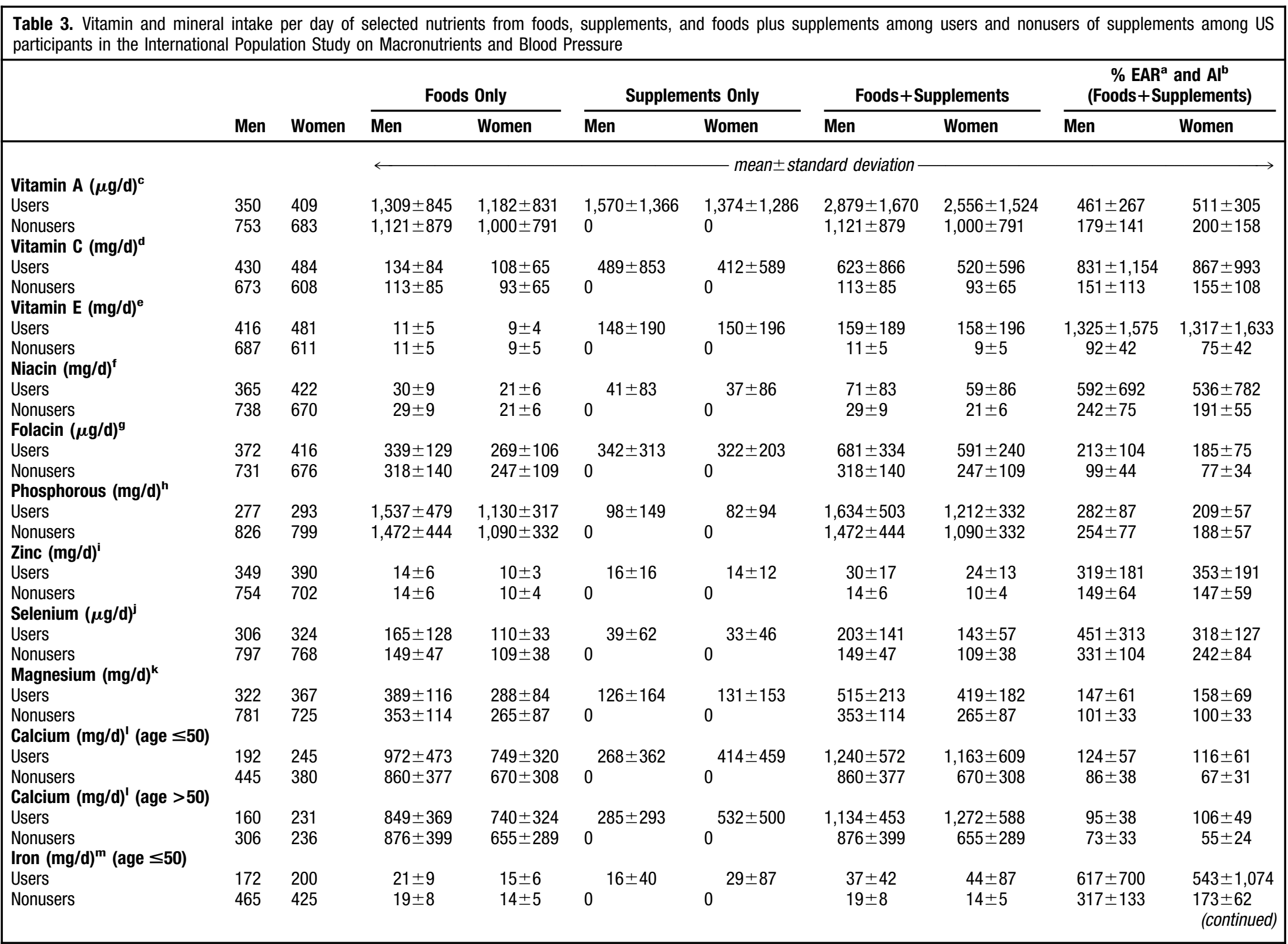




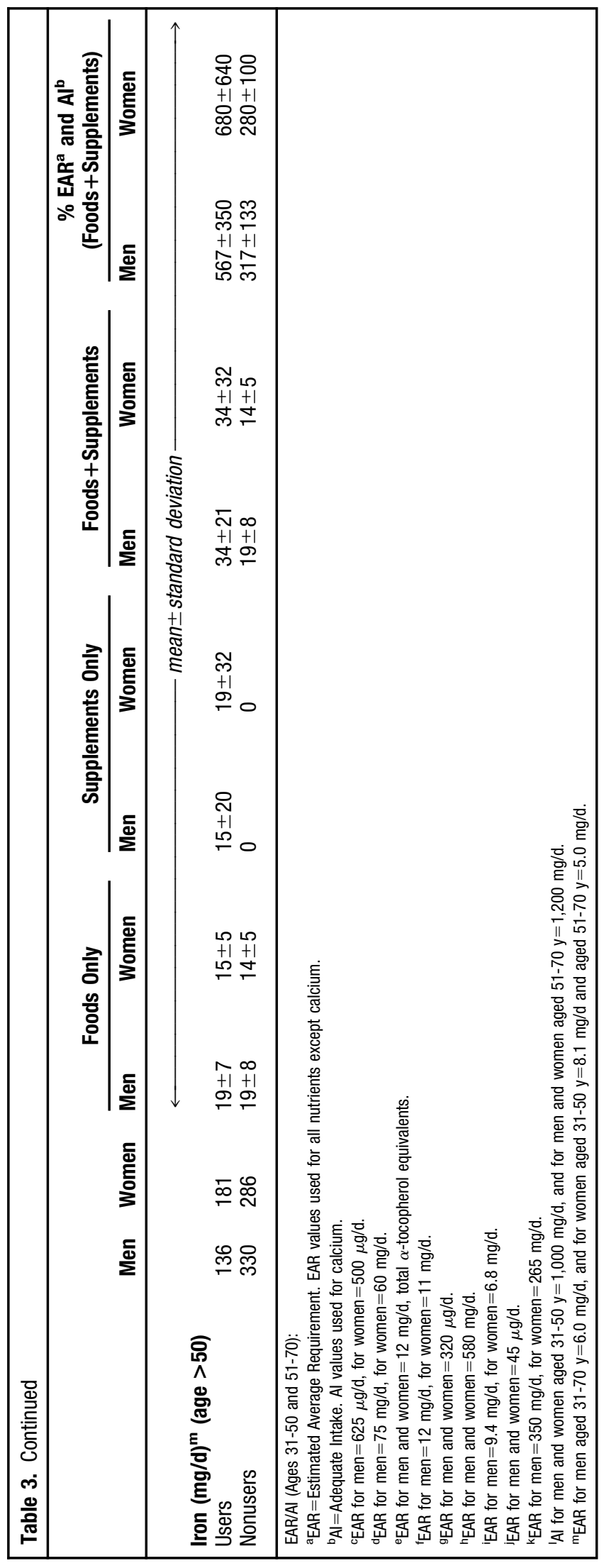

Table 4. Supplement users among US participants in the International Population Study on Macronutrients and Blood Pressure with intakes exceeding Upper Limits (ULS)

\begin{tabular}{|lrrr|}
\hline $\begin{array}{l}\text { Nutrients and level exceeding } \\
\text { UL }\end{array}$ & $\begin{array}{l}\text { Men } \\
(\mathbf{n})\end{array}$ & $\begin{array}{l}\text { Women } \\
(\mathbf{n})\end{array}$ & $\begin{array}{l}\text { Total } \\
(\mathbf{n})\end{array}$ \\
\hline Folacin $(\geq 1,000 \mu \mathrm{g} / \mathrm{d})$ & 8 & 6 & 14 \\
Vitamin $\mathrm{E}(\geq 1,000 \mathrm{mg} / \mathrm{d})$ & 3 & 3 & 6 \\
Magnesium $(\geq 350 \mathrm{mg} / \mathrm{d})$ & 21 & 32 & 53 \\
Zinc $(\geq 40 \mathrm{mg} / \mathrm{d})$ & 24 & 10 & 34 \\
Selenium $(\geq 400 \mu \mathrm{g} / \mathrm{d})$ & 3 & 0 & 3 \\
Calcium $(\geq 2,500 \mathrm{mg} / \mathrm{d})$ & 1 & 3 & 4 \\
Niacin $(\geq 35 \mathrm{mg} / \mathrm{d})$ & 105 & 97 & 202 \\
Vitamin $\mathrm{C}(\geq 2,000 \mathrm{mg} / \mathrm{d})$ & 14 & 15 & 29 \\
\hline
\end{tabular}

\section{Mineral Intakes from Foods, Supplements, and Foods Plus Supplements}

The most commonly consumed mineral from supplements was calcium (Table 3). For five (of the six) minerals (ie, phosphorus, iron, magnesium, selenium, and zinc) studied, average intake from food alone was as high or higher than the EARs, but average intake of calcium was less than the AI. Mean phosphorus and magnesium intakes from food were higher among users than nonusers of supplements. Among dietary supplement users, intakes of phosphorus, iron, magnesium, selenium, and zinc from foods plus supplements exceeded $100 \%$ of the EARs, but for calcium for older supplement users total intake was below AI.

\section{Dietary Supplement Use and ULs of Intakes}

A total of 202 participants had intakes of niacin from supplements that exceeded the UL (Table 4). Niacin was the nutrient with the largest number of participants who consumed amounts greater than or equal to the UL. For 53, 34, and 29 participants, magnesium, zinc, and vitamin C ULs, respectively, were also reached or exceeded.

\section{DISCUSSION}

In the US INTERMAP study of middle-aged men and women, approximately half of US participants used supplements, of whom approximately half used non-NDSlisted supplements. Percentage of users varied by sex, age, ethnicity, years of education, geographic location, lifestyle characteristics, and health status. Women, older adults, Asian Americans, those with higher education, and former cigarette smokers were more likely to use supplements. There was a wide range in percentage users by ethnicity, and by population sample. Substantiating reports on increasing use of botanicals and other alternative supplements in the United States, sizeable proportions of INTERMAP participants used non-NDS supplements, $23 \%$ overall. Supplement users had mean total intakes-from foods plus supplements-of selenium, zinc, phosphorus, magnesium, vitamins $\mathrm{C}$ and $\mathrm{E}$, niacin, and folate $>100 \%$ of the EARs. For supplements such as vitamins $\mathrm{E}$ and $\mathrm{C}$, supplement users had intakes from foods plus supplements that were $>700 \%$ of the EARs. 
Some participants had intakes of nutrients from supplements alone that exceeded the ULs of safe intake.

Some demographic patterns of supplement use observed in INTERMAP were similar to those of other studies; notably, by sex, age, and education (11,23-26). Unlike other studies, we found that Asian Americans (mostly Japanese migrants to Hawaii) were the ethnic group with the greatest percentage of supplement use. In the third National Health and Nutrition Examination Survey, this proportion was highest for non-Hispanic white Americans compared with minority groups; Asian Americans were not identified as a separate ethnic group (1). In the Vitamins and Lifestyle Study (23) investigation of vitamin and mineral use, white people were the highest percent users among adults aged 50 to 75 years in western Washington, Asians the lowest. In apparent contrast to our finding. In the Vitamins and Lifestyle Study, Asian participants were from western Washington State; in our study, Asian participants were predominantly JapaneseAmericans from Hawaii. Like INTERMAP, the Multiethnic Cohort Study reported that Asian Americans mainly of Japanese ancestry were the highest proportion of supplement users compared to African Americans, native Hawaiians, and Latinos (26).

Findings for some of the lifestyle factors, like smoking, were consistent with those of other studies. Current cigarette smokers reported less supplement use, reflecting commonality of their poorer health behaviors $(5,26)$.

\section{Although supplement use can enhance micronutrient intake, some participants were consuming amounts that were excessive when compared with dietary requirements.}

Some studies report that supplement use is more common among those who classify themselves as being "healthy" than "not healthy" $(8,27)$. We found a positive, nonsignificant association between any supplement use and presence of diabetes or stroke. The Beaver Dam Study (5) reported that middle-aged men with a history of heart disease were more likely to use a supplement than those without this history. The Vitamins and Lifestyle Study also found a higher proportion of respondents with medical conditions to be users of dietary supplements. In a review on use of dietary supplements, Halsted (28) comments that those with intractable chronic and fatal diseases tend to turn to herbal supplements more often than other patient groups. In the INTERMAP study, we did not collect information on factors motivating supplement use. The Vitamins and Lifestyle Study results reported that supplement consumers may be motivated to self-treatment (23).

More people diagnosed with a disease or using prescription medication for hypertension/cardiovascular disease used NDS-listed supplements only than non-NDS-listed supplements. There are reports from several studies assessing intakes of specific supplements in relation to disease diagnosis (eg, antioxidants, folate, calcium, or vita- min D) $(26,29,30)$. People with a disease condition may be more likely to take a supplement with a research record than a herbal/botanical/nontraditional supplement with an uncertain or unknown influence on health (31).

It has been stated that supplementation with a formulation that is close to $100 \%$ Daily Value can reduce prevalence of suboptimal micronutrient status, particularly among older adults (31). However, if nutrient intake is already adequate, then it is questionable whether supplement use improves micronutrient profile (32). The contribution of foods to micronutrient adequacy varies from one nutrient to another. In INTERMAP, we observed that intakes from foods only for some nutrients, especially among women, did not meet $100 \%$ of the EAR (eg, folate and vitamin E). Supplement use substantially increased amounts of these nutrients. For vitamin E, supplement use increased intake greatly (eg, intake from food alone among supplement users was $75 \%$ to $100 \%$ of the EARs and from supplements alone was $>1,000 \%$ of the EAR).

Many participants in our study met $100 \%$ of the DRIs for some nutrients from food consumption alone. For phosphorus, niacin, and vitamin $\mathrm{C}$, food alone provided an adequate intake meeting the EAR. Among such participants, benefit of supplement intake is undetermined. These data also confirm that meeting the DRIs by diet alone is possible.

Although supplement use can enhance micronutrient intake, some participants were consuming amounts that were excessive when compared with dietary requirements. Similar to results reported by Troppmann and colleagues (15) and Dwyer and colleagues (13), we identified almost 202 participants with niacin intakes $\geq 35$ $\mathrm{mg} /$ day. The consistent reports of high niacin intake from supplements may reflect prescription of large doses of this supplement for lipid lowering (33). There were a few other participants with intakes of other supplements that were greater than or equal to ULs, indicating possible adverse effects on health, including intakes of vitamin $\mathrm{E}$ $\geq 1,000 \mathrm{mg} /$ day, calcium $\geq 2,500 \mathrm{mg} /$ day, and magnesium $\geq 350 \mathrm{mg} /$ day. ULs are set to relate to total intake from food and supplements. Megadosing of certain micronutrients from supplements alone is apparently occurring and merits attention.

One of the strengths of our study is the extensive data on non-NDS supplement use (ie, intake of supplements of questionable or unknown values). The INTERMAP level of non-NDS supplement use was higher than that reported by the Slone Survey of Americans, where 14\% of the population took a herbal supplement in the preceding week (25). There are few reports about intakes of herbal/ botanical supplements and health conditions (25,34).

One of the criticisms of dietary supplement data based on a single 24-hour recall is that micronutrient intake may be underestimated due to variations in supplement intake and due to recall errors. In INTERMAP we used four 24-hour recalls, thereby reducing this error.

Results from the INTERMAP study show that high proportions of middle-aged Americans from population samples across the country used dietary supplements in the late 1990s. These proportions varied by age, sex, ethnicity, education, geographic region, BMI, smoking habits, and medical status, as did types and amounts of supplements used. Supplement use sizably increased di- 
etary intakes of some micronutrients (eg, vitamins $\mathrm{C}$ and $\mathrm{E})$, where amounts from supplements were several-fold greater than from foods. Sizeable proportions of these Americans-almost one quarter overall- reported use of supplements containing nonvitamin and nonmineral materials, sometimes not identifiable or quantifiable (ie, supplements of questionable value). Health care providers need to discuss dietary supplement use with patients, and vice versa. Our data underscore the importance of assessing dietary supplement use in diet-related research. These data also underscore the importance of increased attention by medical care and public health to amounts, types, and merits/problems of supplement use by the US population.

\section{CONCLUSIONS}

Dietetics and other health care professionals, including nutrition researchers, need to assess intakes of supplements, and use the findings in their work for public policy enhancement. Also, because use of dietary supplements can change nutrient intake dramatically, it is important that dietetics professionals assess dietary supplement intake.

The authors thank all INTERMAP study staff for their collaborative efforts (a list of staff members from participating US centers, coordinating centers, the Steering and Editorial Committee, and Advisory Committee is provided in reference 21). This research was supported by grant No. 5-RO1-HL50490 from the National Heart, Lung, and Blood Institute, National Institutes of Health, Bethesda, MD, and by the Chicago Health Research Foundation.

\section{References}

1. Use of dietary supplements in the United States, 1988-94: Data from the National Health Examination Survey, the National Health and Nutrition Examination Surveys, and the Hispanic Health and Nutrition Examination Survey. Series 1, No. 244. Available at: http://www.cdc.gov/nchs/products/pubs/pubd/series/ sr11/pre-241/sr11_244.htm. Accessed April 12, 2005.

2. Ervin RB, Wright JD, Kennedy-Stephenson J. Use of Dietary Supplements in the United States, 1988-94. Hyattsville, MD: National Center for Health Statistics; 1999. Advance Data From Vital and Health Statistics, No. 244:1-14.

3. Blendon RJ, DesRoches CM, Benson JM, Brodie M, Althman DE. Americans' views on the use and regulation of dietary supplements. Arch Intern Med. 2001; 161:805-810.

4. Medeiros DM, Bock MA, Ortiz M, Raab C, Read M, Schutz HG, Sheehan ET, Williams DK. Vitamin and mineral supplementation practices of adults in seven western states. J Am Diet Assoc. 1989;89:383-386.

5. Lyle BJ, Mares-Perlman JA, Klein BEK, Klein R, Greger JL. Supplement users differ from nonusers in demographic, lifestyle, dietary, and health characteristics. J Nutr. 1998;128:2355-2362.

6. Rhee KS, Stubbs AC. Health food users in two Texas cities. J Am Diet Assoc. 1976;68:542-545.

7. Bates CJ, Prentice A, van der Pols JC, Walmsley C,
Pentieva KD, Finch S, Smithers G, Clarke PC. Estimation of the use of dietary supplements in the National Diet and Nutrition Survey: People aged 65 years and over. An observed paradox and a recommendation. Eur J Clin Nutr. 1998;52:917-923.

8. Eliason BC, Myszkowski J, Marbella A, Rasmann DN. Use of dietary supplements by patients in a family practice clinic. J Am Board Fam Pract. 1996; 9:249-253.

9. Heimbach JT. Using the National Nutrition Monitoring System to profile dietary supplement use. J Nutr. 2001;131:1335S-1338S.

10. Greger JL. Dietary supplement use: Consumer characteristics and interests. J Nutr. 2001;131:1339S1343S.

11. Balluz LS, Kieszak SM, Philen RM, Mulinare J. Vitamin and mineral supplement use in the United States. Arch Fam Med. 2000;9:258-262.

12. Subar AF, Block G. Use of vitamin and mineral supplements: Demographics and amounts of nutrients consumed. The 1987 Health Interview Survey. Am J Epidemiol. 1990;132:1091-1101.

13. Dwyer JT, Garceau AO, Evans M, Li D, Lytle L, Hoelscher D, Niclas TA, Zive M. Do adolescent vitamin-mineral supplement users have better nutrient intakes than nonusers? Observations from the CATCH tracking study. J Am Diet Assoc. 2001;101: 1340-1346.

14. Looker AC, Sempos CT, Johnson CL, Yetley EA. Comparison of dietary intakes and iron status of vitamin-mineral supplement users and nonusers aged 1-19 years. Am J Clin Nutr. 1987;46:665-672.

15. Troppman L, Gray-Donald K, Johns T. Supplement use: Is there any nutritional benefit? J Am Diet Assoc. 2002;102:818-825.

16. Recommended Dietary Allowances, 10th ed. Washington, DC: National Academy Press; 1989.

17. Institute of Medicine, Food and Nutrition Board. Dietary Reference Intakes for Calcium, Phosphorus, Magnesium, Vitamin D, and Fluoride. Washington, DC: National Academy Press; 1999.

18. Institute of Medicine, Food and Nutrition Board. Dietary Reference Intakes for Thiamin, Riboflavin, Niacin, Vitamin B6, Folate, Vitamin B12, Pantothenic Acid, Biotin and Choline. Washington, DC: National Academy Press; 2000.

19. Institute of Medicine, Food and Nutrition Board. Dietary Reference Intakes for Vitamin A, Vitamin $K$, Arsenic, Boron, Chromium, Copper, Iodine, Iron, Manganese, Molybdenum, Nickel, Silicon, Vanadium and Zinc. Washington, DC: National Academy Press; 2001.

20. Institute of Medicine, Food and Nutrition Board. Dietary Reference Intakes: Applications in Dietary Assessment. Washington, DC: National Academy Press; 2000.

21. Stamler, J, Elliott P, Dennis B, Dyer AR, Keteloot H, Liu K, Ueshima H, Zhou BF. INTERMAP: Background, aims, design, methods, and descriptive statistics (non-dietary). J Hum Hypertens. 2003;17:591-608.

22. Dennis B, Stamler J, Buzzard M, Conway R, Elliott P, Moag-Stahlberg A, Okuda N, Robertson C, Robinson F, Schakel S, Stevens M, Van Heel N, Zhao L, Zhou BF. 
INTERMAP: The dietary data-process and quality control. J Hum Hypertens. 2003;17:609-622.

23. Satia-Abouta J, Kristal AR, Patterson RE, Littman AJ, Stratton KL, White E. Dietary supplement use and medical conditions: The VITAL study. Am J Prev Med. 2003;24:43-45.

24. Ervin RB, Wright JD, Reed-Gillette D. Prevalence of leading types of dietary supplements used in the Third National Health and Nutrition Examination Survey, 1988-94. Hyattsville, MD: National Center for Health Statistics; 2004. Advance Data from Vital and Health Statistics, No. 349:1-8.

25. Kauffman DW, Kelly JP, Rosenberg L, Anderson T, Mitchell AA. Recent patterns of medication use in the ambulatory adult population of the United States: The Slone Survey. JAMA. 2002;287:337-344.

26. Foote JA, Murphy SP, Wilkens LR, Hankin JH, Henderson BE, Kolonel LN. Factors associated with dietary supplement use among healthy adults of five ethnicities. The Multiethnic Cohort Study. Am J Epidemiol. 2003;157:888-897.

27. Slesinski MH, Subar AF, Kahle LL. Trends in use of vitamin and mineral supplements in the United States: The 1987 and 1992 National Health Interview Surveys. J Am Diet Assoc. 1995;95:921-923.

28. Halsted CH. Dietary supplements and functional foods: 2 sides of a coin? Am J Clin Nutr. 2003;77 (suppl 4):S1001-S1007.

29. Bender MM, Levy AS, Schucker RE, Yetley EA. Trends in prevalence and magnitude of vitamin and mineral supplement usage and correlation with health status. J Am Diet Assoc. 1992;92:1096-1101.

30. Kim I, Williamson DF, Byres T, Koplan JP. Vitamin and mineral supplement use and mortality in a US cohort. Am J Public Health. 1993;83:546-550.

31. McKay DL, Perrone G, Rasmussen H, Dallal G, Hartman W, Cao G, Prior RL, Roubenoff R, Blumberg JB. The effects of a multivitamin/mineral supplement on micronutrient status, antioxidant capacity, and cytokine production in healthy older adults consuming a fortified diet. J Am Coll Nutr. 2000;19:613-621.

32. Payette H, Gray-Donald K. Do vitamin and mineral supplements improve the dietary intake of elderly Canadians? Can J Public Health. 1991;82:58-60.

33. Kwiterovich PO. Beyond Cholesterol: The Johns Hopkins Complete Guide for Avoiding Heart Disease. Baltimore, MD: The Johns Hopkins University Press; 1989: 275-278.

34. Radimer KL, Subar AF, Thompson FE. Nonvitamin, nonmineral dietary supplements: Issues and findings from NHANES III. J Am Diet Assoc. 2000;100:447454 . 